\title{
Investigation into the biological properties of the olive polyphenol, hydroxytyrosol: mechanistic insights by genome-wide mRNA-Seq analysis
}

\author{
Haloom Rafehi • Andrea J. Smith • Aneta Balcerczyk • \\ Mark Ziemann · Jenny Ooi · Shanon J. Loveridge • \\ Emma K. Baker • Assam El-Osta • Tom C. Karagiannis
}

Received: 1 July 2011/Accepted: 13 September 2011/Published online: 28 September 2011

(C) Springer-Verlag 2011

\begin{abstract}
The medicinal properties of the leaves and fruit of Olea Europaea (olive tree) have been known since antiquity. Numerous contemporary studies have linked the Mediterranean diet with increased health. In particular, consumption of olive oil has been associated with a decreased risk of cardiovascular disease and certain cancers. Increasingly, there has been an interest in the biological properties of polyphenols, which are minor constituents of olive oil. For example, hydroxytyrosol has been shown to be a potent antioxidant and has anti-atherogenic and anticancer properties. The overall aim of this study was to provide insights into the molecular mechanisms of action of hydroxytyrosol using genome-wide mRNA-Seq. Initial experiments were aimed at assessing cytotoxicity, apoptosis and cell cycle effects of hydroxytyrosol in various cell lines.
\end{abstract}

Electronic supplementary material The online version of this article (doi:10.1007/s12263-011-0249-3) contains supplementary material, which is available to authorized users.

H. Rafehi · S. J. Loveridge · T. C. Karagiannis $(\bowtie)$ Epigenomic Medicine, Baker IDI Heart and Diabetes Institute, The Alfred Medical Research and Education Precinct,

75 Commercial Road, Melbourne, VIC, Australia

e-mail: tom.karagiannis@bakeridi.edu.au

H. Rafehi · A. El-Osta · T. C. Karagiannis Department of Pathology, The University of Melbourne, Parkville, VIC, Australia

\section{A. J. Smith}

Molecular Radiation Biology, Peter MacCallum Cancer Centre, Melbourne, VIC, Australia

\footnotetext{
A. Balcerczyk - M. Ziemann - J. Ooi - S. J. Loveridge

E. K. Baker · A. El-Osta

Epigenetics in Human Health and Disease, Baker IDI Heart and Diabetes Institute, The Alfred Medical Research and Education Precinct, Melbourne, VIC, Australia
}

The findings indicated a dose-dependent reduction in cell viability in human erythroleukemic K562 and human keratinocytes. When comparing the viability in parental CEM-CCRF and R100 cells (which overexpress the P-glycoprotein pump), it was determined that the R100 cells were more resistant to effects of hydroxytyrosol suggesting efflux by the multi-drug resistance pump. By comparing the uptake of Hoechst 33342 in the two cell lines that had been pretreated with hydroxytyrosol, it was determined that the polyphenol may have P-glycoprotein-modulating activity. Further, initial studies indicated modest radioprotective effects of relatively low doses of hydroxytyrosol in human keratinocytes. Analysis of mRNA sequencing data identified that treatment of keratinocytes with $20 \mu \mathrm{M}$ hydroxytyrosol results in the upregulation of numerous antioxidant proteins and enzymes, including heme oxygenase-1 (15.46fold upregulation), glutaredoxin (1.65) and glutathione peroxidase (1.53). This may account for the radioprotective

Present Address:

E. K. Baker

Stem Cell Regulation Unit, St. Vincent's Institute,

Fitzroy, VIC, Australia

A. El-Osta

Epigenomic Profiling Facility, Baker IDI Heart and Diabetes Institute, The Alfred Medical Research and Education Precinct, Melbourne, VIC, Australia

A. El-Osta

Department of Medicine, Monash University,

Melbourne, VIC, Australia 
activity of the compound, and reduction in oxidative stress suggests a mechanism for chemoprevention of cancer by hydroxytyrosol. Alteration in the expression of transcription factors may also contribute to the anti-cancer effects described in numerous studies. These include changes in the expression of STAT3, STAT6, SMAD7 and ETS-1. The telomerase subunit TERT was also found to be downregulated in K562 cells. Overall, our findings provide insights into the mechanisms of action of hydroxytyrosol, and more generally, we identify potential gene candidates for further exploration.

Keywords Hydroxytyrosol - Olive polyphenol . Olive oil $\cdot$ Radioprotection $\cdot$ mRNA-Seq

\section{Introduction}

The medicinal properties of the leaves and fruit of Olea Europaea (olive tree) have been known since antiquity. Evidence indicates that the Cretans have been cultivating olive trees and using olive oil for over 5,000 years. Further, the ancient Spartan (a community renowned for its health and supreme military prowess) diet was based largely on organic plant products with a particular emphasis on virgin olive oil. Numerous contemporary studies have linked the more modern Mediterranean diet (an adaptation of the traditional versions) with increased health (Trichopoulou et al. 2000; Nadtochiy and Redman 2011; Pauwels 2011; El and Karakaya 2009). In particular, consumption of olive oil has been associated with a decreased risk of cardiovascular disease and certain cancers (Pauwels 2011).
Increasingly, there has been an interest in the biological properties of polyphenols, which are minor constituents of olive oil (Raederstorff 2009). For example, hydroxytyrosol has been shown to be a potent antioxidant and has antiatherogenic and anti-cancer properties (Granados-Principal et al. 2010). Early studies indicated that consumption of olive oil resulted in changes in lipid profiles, and that it was beneficial for cholesterol absorption and deposition and therefore prevention of atherosclerosis (Wagner 1957; Okey et al. 1959; Member and Bruger 1945). Many other beneficial effects of olive oil have been described, including a reduction in hypertension and improvement of diabetes, and reduced inflammation (Puertollano et al. 2007; Yaqoob et al. 1998). It has also been shown to have antioxidant properties and to result in the reduction of lipid peroxidation of membranes (Mataix et al. 2006; Quiles et al. 1999; Huertas et al. 1992).

Olive oil has been identified as a major component of the Mediterranean diet accounting for the reduced incidence of cardiovascular diseases in those regions (Huang and Sumpio 2008; Serra-Majem et al. 2003; Alarcon de la Lastra et al. 2001). These beneficial effects were initially believed to be due to the oleic acid content of olive oil; however, there has been a shift in research interest, with a growing focus on other minor components of olive oil, such as the polyphenols (Fig. 1) (Visioli and Bernardini 2011). Hydroxytyrosol is a relatively well-characterised olive polyphenol (Granados-Principal et al. 2010). It has been shown to be a potent antioxidant which can scavenge the superoxide anion, hydrogen peroxide, hypochlorous acid (Granados-Principal et al. 2010). Also, it has been shown to have anti-atherogenic, anti-thrombotic and
Fig. 1 Chemical structures of the relevant olive phenolic compounds<smiles>COc1cc(CCO)ccc1O</smiles>

Homovanillic alcohol<smiles>C/C=C1/C(OCC)OC=C(C(C)=O)C1CC(=O)OCCc1ccc(O)c(O)c1</smiles><smiles>OCCc1ccc(O)cc1</smiles>

Tyrosol<smiles>OCCc1ccc(O)c(O)c1</smiles>

Hydroxytyrosol 
anti-inflammatory properties (Gonzalez-Santiago et al. 2006; Marrugat et al. 2004; Puel et al. 2008). Numerous studies have also shown that hydroxytyrosol may be a potential anti-cancer agent (Bouallagui et al. 2011; Sirianni et al. 2010; Han et al. 2009; Fabiani et al. 2002). In promyelocytic leukemic cells and colon adenoma, it has been shown to induce apoptosis, cause cell cycle arrest and limit cell growth and proliferation (Della Ragione et al. 2000). The overall aim of this study was to provide insights into the molecular mechanisms of action of hydroxytyrosol using genome-wide mRNA-Seq. Initial experiments were aimed at assessing cytotoxicity, apoptosis and cell cycle effects of hydroxytyrosol in various cell lines. Given that we are interested in the potential topical radioprotective properties of hydroxytyrosol, we evaluated gene expression changes in human keratinocytes at the relatively low concentration of $20 \mu \mathrm{M}$. To obtain some insights into the mechanism of cell death and apoptosis, we explored gene changes induced by 20 and $100 \mu \mathrm{M}$ hydroxytyrosol in human erythroleukemic K562 cells.

\section{Methods}

\section{Chemical compounds}

Concentrated stocks of the olive polyphenols hydroxytyrosol $(2 \mathrm{mg} / \mathrm{mL}$ in ethanol, Cayman Chemicals, Ann Arbor, MI, USA), tyrosol (Fluka-Sigma, St. Louis, MO, USA), oleuropein (Indofine Chemical, Hillsborough, NJ, USA) and homovanillic alcohol (Sigma) were prepared in absolute ethanol and stored at $-80^{\circ} \mathrm{C}$ until use. Prior to use in experiments, stocks were diluted appropriately in sterile Dulbecco's PBS without $\mathrm{Ca}^{2+} / \mathrm{Mg}^{2+}$. Stock solutions (10 mM) of Hoechst 33342 (Sigma) were prepared in $45 \%$ methanol/ $\mathrm{dH}_{2} \mathrm{O}$ and further diluted in $\mathrm{dH}_{2} \mathrm{O}$ prior to use.

\section{Routine cell culture}

Human keratinocytes (FEP-1811) were grown in keratinocyte-SFM (K-SFM) medium (Invitrogen, Carlsbad, CA, USA-serum-free medium) supplemented with $2 \mathrm{mM}$ L-glutamine, epidermal growth factor, bovine pituitary extract and 80 units gentamicin (Hurlin et al. 1991). As required, single cell suspensions were prepared by trypsinisation $(0.05 \%$ trypsin/EDTA solution, Invitrogen) for 5-10 min. CEM-CCRF cells were grown in the $\alpha$-MEM containing $10 \%$ foetal bovine serum (FBS) and 80 units of gentamicin. Similarly, P-glycoprotein (PGP)-overexpressing R100 cells were grown in $\alpha$-MEM containing $10 \%$ FBS, 80 units gentamicin and $100 \mathrm{ng} / \mathrm{mL}$ vinblastine. R100 cells were cultured in $\alpha$-MEM/FBS/gentamicin media without vinblastine for 7 days prior to use in experiments.
K562 cells were grown in RPMI-1640 medium supplemented with $10 \%$ FBS, 2 mM L-glutamine and 80 units gentamicin (GIBCO-Invitrogen). All cells were incubated in a humidified atmosphere at $5 \% \mathrm{CO}_{2}$ and $37^{\circ} \mathrm{C}$.

\section{Cell growth and apoptosis}

Cells were seeded into $25-\mathrm{mL}$ flasks, in $5 \mathrm{~mL}$ of the appropriate media. Cells were incubated at $5 \% \mathrm{CO}_{2}$ and $37^{\circ} \mathrm{C}$ overnight and were treated with various concentrations of hydroxytyrosol $(0-1,000 \mu \mathrm{M})$. Following 24-h incubation, the cell numbers were determined using a haemocytometer. CellTiter-Blue ${ }^{\circledR}$ and ApoOne homogeneous Caspase $3 / 7^{\circledR}$ kits were used to examine the effects of HT on cell viability and apoptosis, respectively, according to the manufacturer's instructions (Promega, Madison, WI, USA). Briefly, cells were seeded at a density of 50,000 cells per well in black 96-well plates and treated with hydroxytyrosol $(0-1,000 \mu \mathrm{M})$ for $24 \mathrm{~h}$. In relevant experiments, cells were treated with $20 \mu \mathrm{M}$ hydroxytyrosol for $24 \mathrm{~h}$ and then irradiated with $2 \mathrm{~Gy}\left({ }^{137} \mathrm{Cs}\right.$ source). CellTiter-Blue $(20 \mu \mathrm{L})$ or ApoOne $(50 \mu \mathrm{L})$ reagent was added, and cells were incubated in foil for 2 or $4 \mathrm{~h}$, respectively, at room temperature. Fluorescence was measured using a VICTOR 3 (PerkinElmer, Waltham MA, USA) plate reader.

Cell cycle analysis

Cells were treated with various concentrations of hydroxytyrosol $(0-1,000 \mu \mathrm{M})$ and incubated for $24 \mathrm{~h}$, after which cells were harvested and suspended in $2 \%$ FBS-PBS. Cells were washed and suspended in ice-cold $1 \mathrm{~mL} 2 \%$ FBS-PBS. Three millilitres of ice-cold $100 \%$ ethanol was then added while vortexing. Cells were rotated overnight at $4^{\circ} \mathrm{C}$, centrifuged at $400 \times g$ for $5 \mathrm{~min}$ and then washed with ice-cold PBS. The cells were then resuspended in $1 \mathrm{~mL}$ of $10 \mu \mathrm{g} / \mathrm{mL}$ propidium iodide (PI), to which $20 \mu \mathrm{L} 1 \mu \mathrm{g} / \mathrm{mL}$ RNase A (Qiagen Inc., Valencia, CA, USA) was added. Cells were again rotated overnight at $4^{\circ} \mathrm{C}$ in the dark. Samples were analysed by flow cytometry (Facs Calibur, Becton-Dickinson, Franklin Lakes, NJ, USA). Fluorescent debris were gated using forward scatter versus orthogonal side scatter, and a secondary gate was placed around the single cell population using a pulse area versus pulse width dot plot. The percentage of cells in each phase of the cell cycle was analysed using FlowJo V7.6 flow cytometry analysis software (Tree Star Inc., Ashland, OR, USA).

Analysis of apoptosis and cell death using annexin/PI staining

Keratinocytes were treated with the relevant concentrations of hydroxytyrosol for $24 \mathrm{~h}$. Cells were then centrifuged and 
suspended in $1 \mathrm{~mL}$ annexin- $\mathrm{V}$ binding buffer (Invitrogen), to which $5 \mu \mathrm{L}$ Annexin-V FITC conjugate (Invitrogen) and $10 \mu \mathrm{L} 10 \mu \mathrm{g} / \mathrm{mL}$ PI were added. Cells were incubated for a further 30 min before being analysed by flow cytometry as described above.

\section{Hoechst 33342 uptake studies}

CEM-CCRF and R100 cells were incubated with the relevant concentrations of hydroxytyrosol prior to incubation with $10 \mu \mathrm{M}$ of Hoechst 33342 for $2 \mathrm{~h}$ at $37^{\circ} \mathrm{C}$. Following incubation, cells were treated with $10 \mu \mathrm{g} / \mathrm{mL}$ PI and were analysed by flow cytometry as described above.

Assessment of PGP expression by flow cytometry

CEM-CCRF and R100 cells in PBS were incubated with MRK-16 antibody (anti-PGP monoclonal antibody; Enzo Life Sciences, Farmingdale, NY, USA) for $1 \mathrm{~h}$. Following incubation, cells were washed and incubated with an FITC-labelled anti-mouse secondary antibody (Millipore, Billerica, MA, USA) for a further $1 \mathrm{~h}$ prior to analysis by flow cytometry as described.

Assessment of PGP expression by quantitative reverse transcriptase PCR (qPCR)

qPCR was performed to determine the fold difference between the expression of the multi-drug resistance (MDR1) gene (PGP pump) in CEM-CCRF and R100 cells. The effect of hydroxytyrosol $(0-500 \mu \mathrm{M})$ on MDR1 expression in R100 cells was also assessed. An Applied Biosystems 7500 Fast Real-Time PCR System was used. Primers were MDR1 (F: 5'-ggaagccaatgcctatgacttta-3', R: $5^{\prime}$-gaaccactgcttcgcttctg- $3^{\prime}$ ) and HMBS (F: $5^{\prime}$-ggcaatgcggct gcaa-3', R: $5^{\prime}$-gggtacccacgcgaatcac- $3^{\prime}$ ) (van den HeuvelEibrink et al. 2002; Vandesompele et al. 2002). 5 pmol of forward and reverse primers were added to cDNA template and FAST SYBR ${ }^{\circledR}$ Green Master Mix (Roche, Basel, Switzerland) to a final volume of $20 \mu \mathrm{L}$. Reactions were incubated at $95^{\circ} \mathrm{C}$ for $10 \mathrm{~min}$, followed by 40 cycles of $95^{\circ} \mathrm{C}$ for $10 \mathrm{~s}$ and $60^{\circ} \mathrm{C}$ for $30 \mathrm{~s}$. MDR 1 was normalised to the level of HMBS.

Sulforhodamine B microtitre plate assay

Keratinocytes were seeded onto 96-well flat-bottomed plates in $0.5 \mathrm{~mL}$ of medium. Cells were treated with various concentrations $(0-1,000 \mu \mathrm{M})$ of the phenolic compounds hydroxytyrosol, oleuropein, homovanillic acid and tyrosol for $24 \mathrm{~h}$. Relevant plates were irradiated with 12 Gy $\left({ }^{137} \mathrm{Cs}\right.$ source). In separate experiments, cells were treated with $20 \mu \mathrm{M}$ hydroxytyrosol and irradiated with varying doses of $\gamma$-rays $(0-12 \mathrm{~Gy})$. Media was then aspirated, and the cells were fixed with $1 \mathrm{~mL} 10 \%$ trichloroacetic acid in $0.9 \% \mathrm{NaCl}$ by incubation for $1 \mathrm{~h}$ at $4^{\circ} \mathrm{C}$. The wells were then washed five times and air-dried for $1 \mathrm{~h}$. Cells were stained with $1 \mathrm{~mL} 0.4 \%$ SRB in $1 \%$ acetic acid for $30 \mathrm{~min}$ at room temperature and then rapidly rinsed with $1 \%$ acetic acid and air-dried. Tris-base $(10 \mathrm{mM}, \mathrm{pH}$ $10.5,2 \mathrm{~mL}$ ) was then added to each well, and absorbance was measured at $550 \mathrm{~nm}$.

\section{Clonogenic survival}

Keratinocytes were incubated for $24 \mathrm{~h}$ with various concentrations $(0-1,000 \mu \mathrm{M})$ of hydroxytyrosol in $25-\mathrm{mL}$ filtercapped flasks at $37^{\circ} \mathrm{C}$ and $5 \% \mathrm{CO}_{2}$. Following incubation, cells were irradiated with 4 or $12 \mathrm{~Gy}\left({ }^{137} \mathrm{Cs}\right.$ source). Cells were washed with $3 \mathrm{~mL}$ of PBS and treated with $1 \mathrm{~mL}$ of $0.01 \%$ pronase and detached from the flask. Cells were collected by centrifugation at $400 \times g$ and suspended in $5 \mathrm{~mL}$ of fresh media. Cell numbers were determined using a Coulter counter (Z2 Series Analyser, Beckman-Coulter) and then cloned in quintuplicate, each petri dish containing a predetermined number of cells in $5 \mathrm{~mL}$ of media. The dishes were incubated for 8 days at $37^{\circ} \mathrm{C}$ and $5 \% \mathrm{CO}_{2}$ to allow for colony formation. Following incubation, media was aspirated and washed with $5 \mathrm{~mL} 0.9 \%$ saline. Colonies were then fixed with $3 \mathrm{~mL}$ of $4 \%$ neutral formalin for $30 \mathrm{~min}$ and then stained with $3 \mathrm{~mL}$ of $0.01 \%$ crystal violet (Hopkin \& Williams Ltd, England) for $1 \mathrm{~h}$. Dishes were washed with $5 \mathrm{~mL} \mathrm{dH}_{2} \mathrm{O}$ and dried overnight. Colonies were counted using a dissecting microscope, and each colony is defined as a cluster of 50 or more cells.

\section{$\gamma \mathrm{H} 2 \mathrm{AX}$ immunofluorescence}

Keratinocytes were treated with various concentrations of hydroxytyrosol $(0-200 \mu \mathrm{M})$ for $24 \mathrm{~h}$. Cells were fixed with $4 \%$ paraformaldehyde at room temperature for $10 \mathrm{~min}$, washed with PBS and permeabilised with the addition of $100 \mu \mathrm{L}$ of $0.1 \%$ Triton $\mathrm{X}-100$ for $10 \mathrm{~min}$ at room temperature. Cells were then washed three times with PBS and blocked with $1 \%$ BSA for $20 \mathrm{~min}$. The primary mouse monoclonal anti-phospho-histone H2AX antibody (Upstate, New York, USA) diluted in 1\% BSA (1:500) was then added to the cells and incubated for $1 \mathrm{~h}$ on a shaker in a dark, humidified chamber at room temperature. Cells were then washed three times with PBS and then incubated with an Alex-488 conjugated secondary goat anti-mouse antibody (1:500 in 1\% BSA) (Molecular Probes, Oregon, USA) for $45 \mathrm{~min}$ on a shaker in the dark, humidified chamber at room temperature. $100 \mu \mathrm{L}$ of Prolong Gold mounting media containing DAPI (Invitrogen) was used. Images were acquired with an Olympus FluoView 1000 confocal 
microscope (Olympus America Inc., PA, USA) using a $\times 63$ oil immersion objective. Foci were then counted and analysed using MetaMorph 7.6 (Universal Imaging Corporation, PA, USA).

\section{Library construction and RNA sequencing}

Total RNA was isolated using TRIZOL (Invitrogen). Cells suspended in TRIZOL were passed through a $21-G$ needle 5 times to ensure proper lysis and then RNA extraction was performed following Qiagen protocol. Genomic DNA contamination was removed by DNAse treatment (Qiagen Inc., Valencia, CA, USA). First strand cDNA synthesis was performed using High-Capacity cDNA Reverse Transcription Kit (Applied Biosystems, Carlsbad, CA, USA), according to the manufacturer's instructions. RNAseq libraries were prepared according to Illumina mRNAseq library preparation kit (cat \# RS-100-0801). Briefly, $8 \mu \mathrm{g}$ of total RNA was taken for mRNA isolation using poly-T oligo-attached magnetic beads. Poly-A mRNA was fragmented with the presence of divalent cations under elevated temperatures. The mRNA fragments were reversetranscribed via SuperScript II (Invitrogen) with random primers. The second strand was synthesised with the addition of RNaseH and DNA Pol I. Double-stranded complementary DNAs (cDNAs) were end-repaired, followed by $3^{\prime}$ adenylation using Klenow fragment $\left(3^{\prime}-5^{\prime}\right.$ exo minus). Then, Illumina (San Diego, CA, USA) paired-end adapters with T-overhangs at their $3^{\prime}$ end were ligated to the cDNAs. Following column purification (Qiagen MinElute), to remove excess of unligated adapter, library cDNA was separated on a $2.0 \%$ agarose gel. Library cDNA in the range of $200 \pm 10 \mathrm{bp}$ fragments was isolated by gel purification (Qiagen) and amplified with 15 cycles of Phusion DNA polymerase mediated PCR $\left(10 \mathrm{~s} 98^{\circ} \mathrm{C}, 30 \mathrm{~s}\right.$ $65^{\circ} \mathrm{C}, 30 \mathrm{~s} 72^{\circ} \mathrm{C}$ ) using oligonucleotides complementary to Illumina sequencing adapters. Column purified libraries were quantified fluorometrically (Invitrogen), and visualised by MultiNA (DNA 2500 kit) electrophoresis for quality assurance. Libraries were diluted to $10 \mathrm{nM}$ and stored at $-20^{\circ} \mathrm{C}$ prior to cluster generation. Denatured DNA samples were diluted to $6 \mathrm{pM}$ prior to cluster generation (v4 cat \# GD-103-4001). Flow cell sequencing of 36-bp tags was conducted on a Genome Analyzer II apparatus (Illumina) according to the manufacturer's protocols using v4 sequencing reagents (cat \# FC-104-4001).

qPCR validation

PCR amplification was performed using an Applied Biosystems 7500 Fast Real-Time PCR System. Primers used in the validation were HPRT-1 (F: tgacactggcaaaacaatgca, R: ggtcctttcaccagcaagct), HMOX-1 (F: tcccctcgagcgtcctcagc,
R: tggggcatgctgtcgggttg), VEGFA (F: tgaggagtccaacatcacca, R: tctctcctatgtgctggcet), IGFBP-3 (F: cctacctgctgccagcgcc, R: ggtgcgtgctggagacggac), CASP-1 (F: ccacaatgggctctgttttt, R: catctggctgctcaaatgaa), JUNB (F: cacctccegtttacaccaac, R: ggaggtagctgatggtggtc), JUND (F: cgcctggaagagaaagtgaa, R: gttgacgtggctgaggactt), IL-6 (F: tccacaagcgecttcggtcc, R: gtggctgtctgtgtggggcg), IL-8 (F: tgcagctctgtgtgaaggtgc, R: tgtgttggcgcagtgtggtcc), CASP-8 (F: tccaaatgcaaactggatga, R: gggcacagactcttttcagg), PECAM-1 (F: tgggtgggagagaggc tgctg, R: cgagggtccetgcagctgtg), IGFBP-6 (F: gcgectgctgtt gcagagga, R: ggctgggagggcgtggtaga), Bcl-2 (F: ggataacgga ggctgggatgcct, R: caagctcccaccagggccaaa), p21 (F: TGCG TTCACAGGTGTTTCTG, R: ATTAGCGCATCACAGTC GC), BCL2L11 (F: AGCCACAAGACAGGAGCCCAG CA, R: GTTCAGCCTGCCTCATGGAAGCCA), COX11 (F: ACTTACGTGGCCGCTGTCGC, R: TCCTCCAAGT CCAGTAGTCTGGCA). 5 pmol of forward and reverse primers, cDNA template and FAST SYBR ${ }^{\circledR}$ Green Master Mix (Roche) were mixed to a final volume of $20 \mu \mathrm{L}$. Reactions were incubated at $95^{\circ} \mathrm{C}$ for $10 \mathrm{~min}$, followed by 40 cycles of $95^{\circ} \mathrm{C}$ for $10 \mathrm{~s}$ and $60^{\circ} \mathrm{C}$ for $30 \mathrm{~s}$. Analysed genes were normalised to the level of HPRT1.

Statistical analyses

Where relevant, analysis of variance was performed (one way Anova), followed by a Dunnett's test. $P<0.05$ was considered significant.

\section{Results}

Hydroxytyrosol reduces cell viability and induces dosedependent apoptosis

The impact of hydroxytyrosol on cell viability and induction of apoptosis was examined in a transformed cell line (keratinocytes) and three cancer cell lines (K562, CEMCCRF and R100 cells), using a cell growth assay (Table 1), by assessing cell viability and caspase activity (Fig. 2) and

Table 1 EC50 values for hydroxytyrosol in the human cell lines assessed using cell viability studies

\begin{tabular}{lc}
\hline Cell line & EC50 $(\mu \mathrm{M})^{\mathrm{a}}$ \\
\hline CEM-CCRF & 338 \\
R100 & 2,562 \\
K562 & 147 \\
Keratinocytes & 547 \\
\hline
\end{tabular}

${ }^{\text {a }}$ From a minimum of three independent experiments for each cell line 

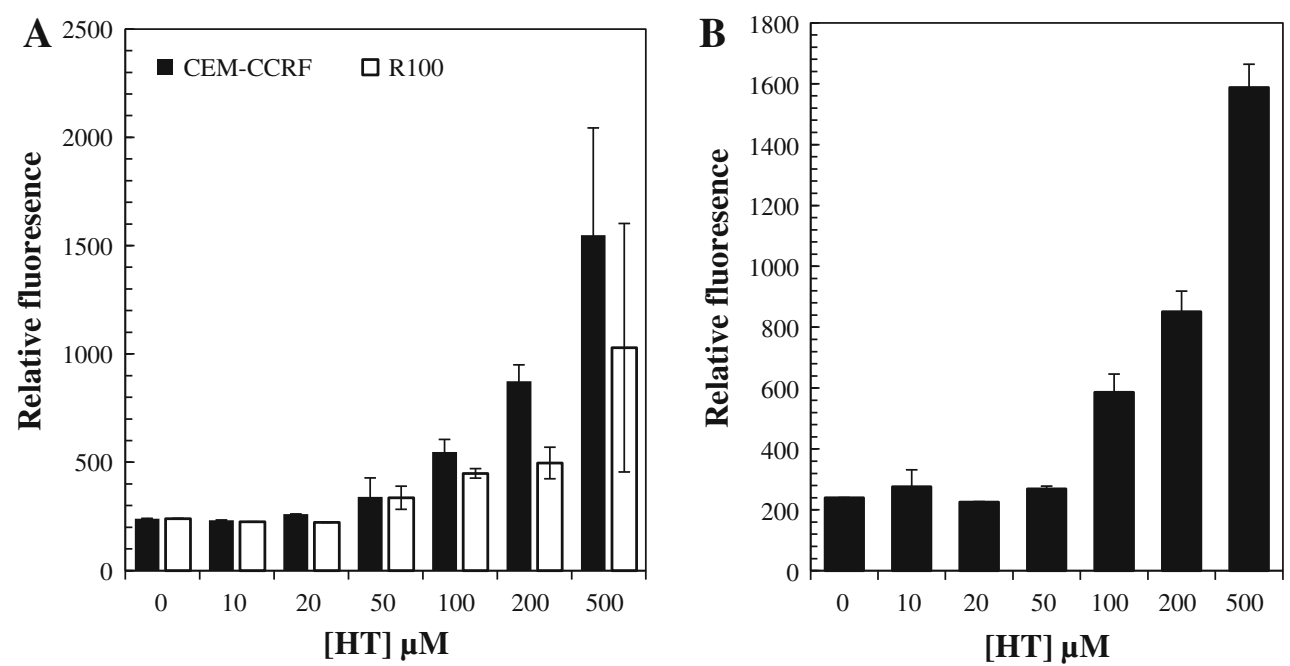

Fig. 2 Caspase 3/7 activity in CEM-CCRF, R100 (a) and K562 (b) cells treated with the indicated concentrations of hydroxytyrosol (HT) for 24 h. Data are representative of at least two independent experiments, and error bars indicate standard error of the mean

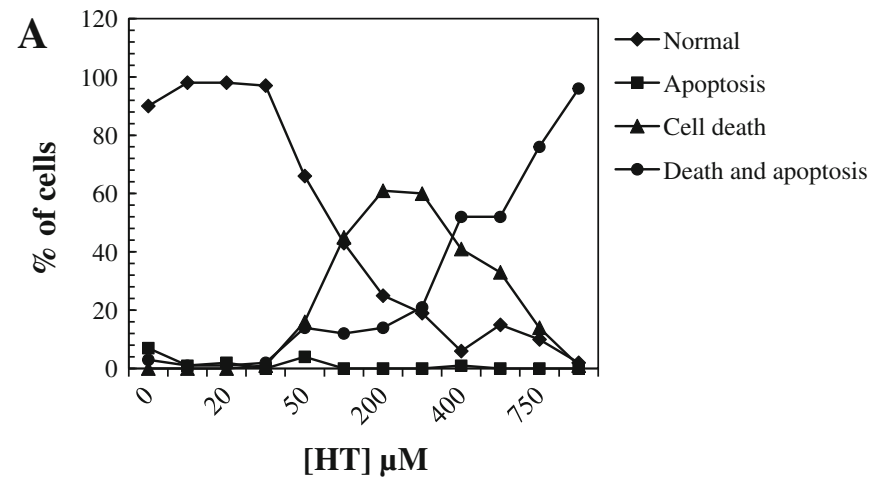

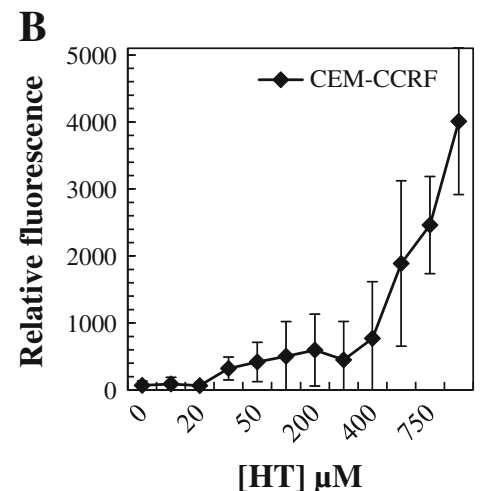

$[\mathrm{HT}] \mu \mathrm{M}$

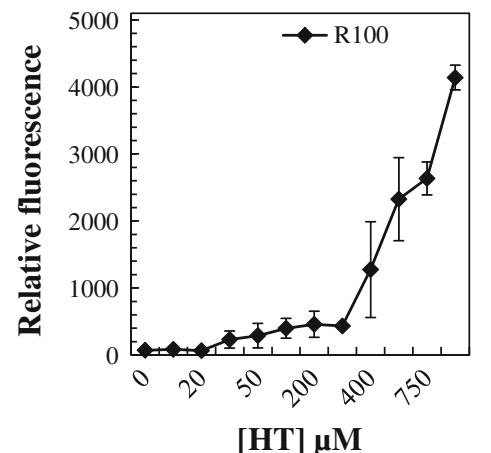

$[\mathrm{HT}] \mu \mathrm{M}$

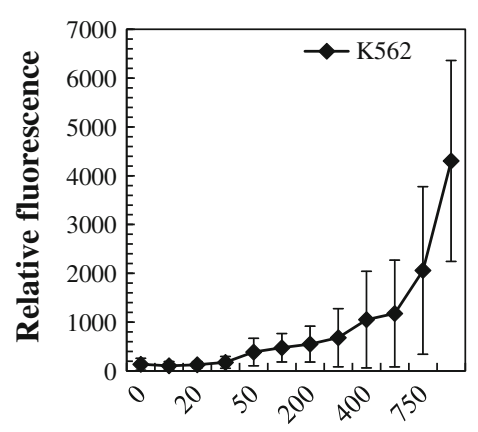

$[\mathrm{HT}] \mu \mathrm{M}$
Fig. 3 Flow cytometric analysis of cell death and apoptosis. Cells were treated with the indicated concentrations of hydroxytyrosol (HT) for $24 \mathrm{~h}$ and stained with PI (cell viability) and Annexin V (apoptosis). a Percentage of K562 cells that were unaffected, undergoing apoptosis, undergoing cell death or both cell death and

with the use of Annexin V/PI staining (Fig. 3). The findings indicate a dose-dependent increase in cell death and apoptosis in all of the cell lines. Interestingly, the parental apoptosis. b Relative fluorescence values for PI (cell death) in the cells treated with hydroxytyrosol. Data are representative of at least two independent experiments, and error bars indicate standard error of the mean

CEM-CCRF cells were more susceptible to hydroxytyrosol-induced cell death and apoptosis than the PGP-overexpressing R100 cells. 
Effect of hydroxytyrosol on PGP expression in CEM-CCRF and R100 cell lines

FACS analysis using MRK-16 (anti-PGP antibody) and qPCR confirmed the overexpression of PGP in R100 cells compared to CEM-CCRF cells (supplementary Figure 1). The findings also indicated that treatment with hydroxytyrosol did not significantly affect PGP expression levels in R100 cells (supplementary Fig. 1). However, the results indicate a decrease in the uptake of the DNA-binding ligand Hoechst 33342 in R100 cells relative to CEM-CCRF, when cells were pretreated with $\leq 300 \mu \mathrm{M}$ hydroxytyrosol (Fig. 4). At higher concentrations of hydroxytyrosol, the ratio of uptake of Hoechst 33342 in CEM-CCRF and R100 cells was similar most likely to the toxic effects of the polyphenol (Fig. 4).

\section{Radioprotection by hydroxytyrosol}

An initial screen of four olive polyphenols for radioprotective potential was performed using a sulforhodamine B microtitre plate assay in keratinocyte cells. It was found that when exposed to 12-Gy irradiation, only hydroxytyrosol displayed radioprotective properties at concentrations examined (supplementary Fig. 2), with optimal radioprotection at $20 \mu \mathrm{M}$ (Fig. 5). Figure 5b shows a dose response in cells treated with $20 \mu \mathrm{M}$ hydroxytyrosol and irradiated at various doses. A dose modification factor (DMF) of 1.35

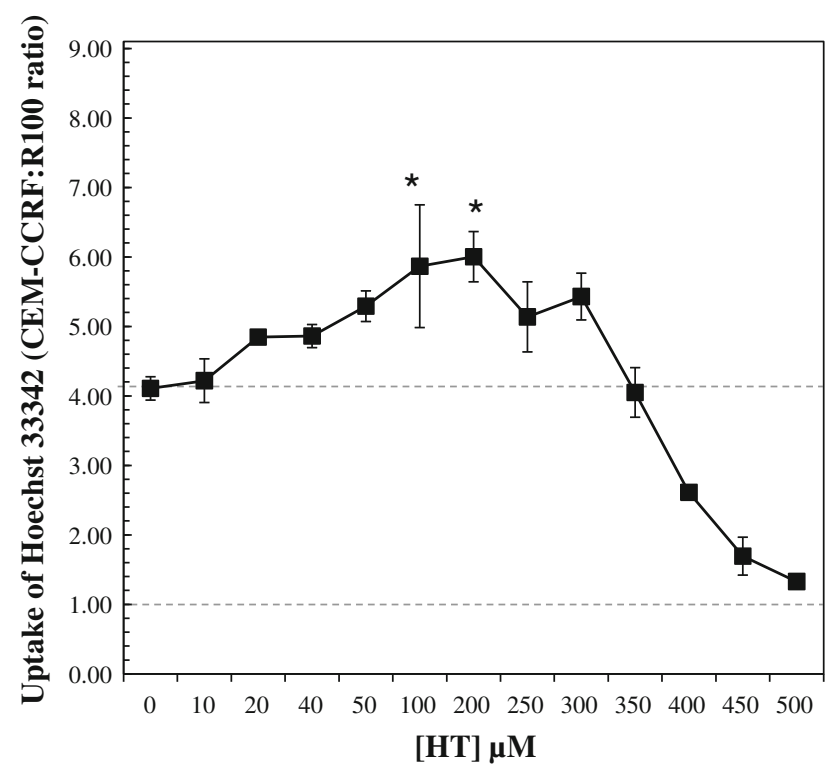

Fig. 4 Flow cytometric analysis of Hoechst 33342 uptake in CEMCCRF and R100 cells that had been pretreated with hydroxytyrosol $(24 \mathrm{~h})$. Cells were then analysed for Hoechst fluorescence using a fluorescence-activated cell sorter. The ratio of Hoechst fluorescence in the two cell lines was calculated. The data are the mean from a total of 12 independent experiments, and error bars indicate standard error of the mean; $* P<0.5$ at $\mathrm{D}_{37}$ was calculated. Figure $5 \mathrm{c}$ and $\mathrm{d}$ show a comparison between hydroxytyrosol-treated cells irradiated at 4 and $12 \mathrm{~Gy}$, respectively, highlighting the modest radioprotective effects of the polyphenol by clonogenic survival. Figure 6 indicates that hydroxytyrosol protects cells from radiation-induced DNA double-breaks (Fig. 6b) and apoptosis (Fig. 6c) as assessed by $\gamma \mathrm{H} 2 \mathrm{AX}$ formation and caspase activity, respectively. Cell cycle analysis indicates that treatment with hydroxytyrosol results in a dosedependent accumulation of cells in the S-phase (Fig. 6a), where it well known that cells are most radioresistant.

Effects of hydroxytyrosol on gene expression in keratinocytes and K562 cells

mRNA sequencing was performed by next-generation sequencing (NGS) at a depth of approximately 20 million mapped reads per sample (Table 2) to determine the effect of hydroxytyrosol on genome-wide gene expression, in keratinocyte cells (treated for $24 \mathrm{~h}$ with $20 \mu \mathrm{M}$ hydroxytyrosol) and K562 cells (24-h treatment, 20 and $100 \mu \mathrm{M}$ ). Reads generated by the Illumina base calling software V1.6 were aligned with Burrows Wheeler Aligner to the human transcriptome database curated by RefSeq (Hg18 build). Raw counts were normalised to adjust for slightly differing data volume across lanes giving the widely used score reads per transcript per million reads. These scores were used to determine relative fold changes, and the conventionally used \pm 1.5 -fold change, which is discernable with qRT-PCR, was defined a significant change in expression. The online program MetaCore (GeneGo Inc., St. Joseph, MI, USA) was used for pathway analysis. Genes examined included those involved in general cellular function such as the cell cycle, as well as specifically those involved in cellular defence against oxidative stress, as well as genes relevant to cancer formation and prevention. The greatest changes in gene expression levels were found in keratinocytes treated with $20 \mu \mathrm{M}$ hydroxytyrosol and K562 cells treated with $100 \mu \mathrm{M}$ of the polyphenol, with approximately $3 \%$ of genes upregulated and $2 \%$ downregulated, respectively (Table 3). K562 cells treated with $20 \mu \mathrm{M}$ hydroxytyrosol were less responsive to treatment, $0.5 \%$ of genes being regulated by the polyphenol (Table 3). Furthermore, Fig. 7 shows that there is little overlap of the gene expression changes between the different cell lines, reflecting the cell-type specificity of hydroxytyrosol. Supplementary Tables 1, 2 and 3 show the 20 most upregulated and downregulated genes for each of the treatment groups and also indicate that there is little overlap between the genes that are most upregulated and downregulated in the two cell lines. The mRNA-Seq findings were validated using qPCR indicating a positive correlation (supplementary Fig. 3). 
Fig. 5 Screening of the radioprotective effects of hydroxytyrosol using the sulforhodamine B microtiter plate assay $(\mathbf{a}, \mathbf{b})$. Human keratinocytes were treated with the indicated concentrations of hydroxytyrosol for $24 \mathrm{~h}$ and irradiated with $12 \mathrm{~Gy}$ (a). In separate experiments, cells were treated with $20 \mathrm{mM}$

hydroxytyrosol for $24 \mathrm{~h}$

followed by irradiation with the indicated doses, and a DMF of 1.35 at $\mathrm{D}_{37}$ was calculated (b). For both experiments, cells were washed and incubated for a further seven days prior to fixing and staining.

Means \pm standard deviations of optical densities at $550 \mathrm{~nm}$ from a representative of at least five independent experiments are shown. Evaluation of the radioprotective properties of hydroxytyrosol by clonogenic survival (c, d). Human keratinocytes cells were treated with the indicated concentrations of hydroxytyrosol for $24 \mathrm{~h}$ prior to irradiation with either 4 (c) or 12 (d) Gy. Means \pm standard deviations of survival from a representative of at least three independent experiments are shown
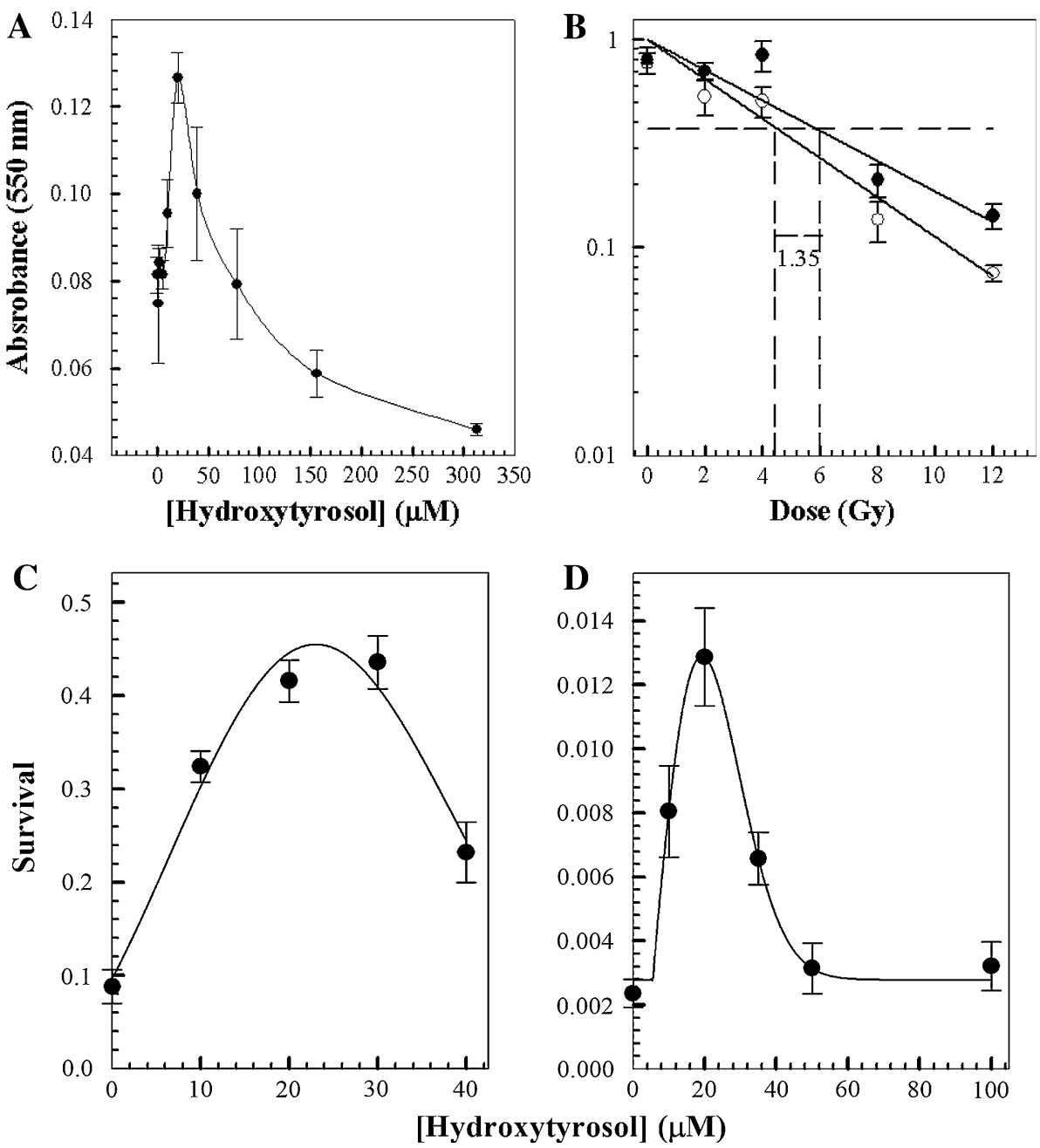

[Hydroxytyrosol] $(\mu \mathbf{M})$

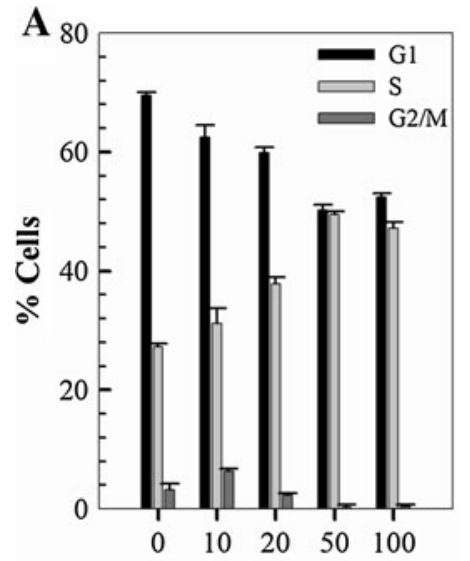

[Hydroxytyrosol] $(\mu \mathrm{M})$
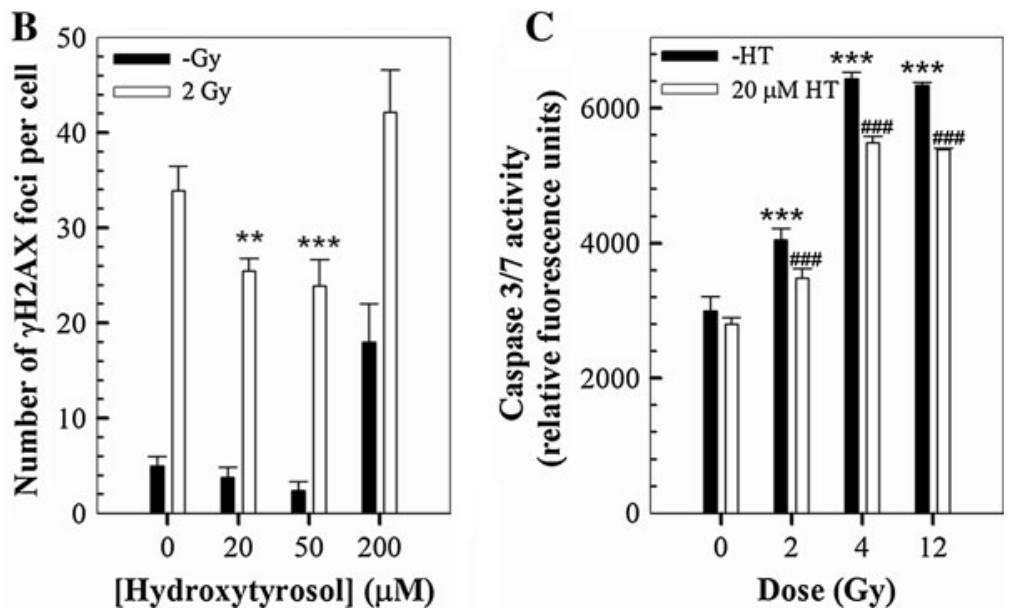

Fig. 6 Evaluation of the effects of hydroxytyrosol on cell cycle and radiation-induced $\gamma \mathrm{H} 2 \mathrm{AX}$ formation and apoptosis in human keratinocytes. Cells were treated with the indicated concentrations of hydroxytyrosol for $24 \mathrm{~h}$ prior to cell cycle analysis (a). In separate experiments, untreated or cells treated with the indicated concentrations of hydroxytyrosol for $24 \mathrm{~h}$ were irradiated with $2 \mathrm{~Gy}$. Cells were then fixed and stained for DNA double-strand breaks using $\gamma \mathrm{H} 2 \mathrm{AX}$ foci as molecular markers (b). In another series of experiments, untreated or cells treated with $20 \mathrm{mM}$ hydroxytyrosol for $24 \mathrm{~h}$ were irradiated with indicated doses. Cells were then washed and incubated for a further $24 \mathrm{~h}$ prior to analysis for apoptosis by monitoring induction of caspases 3 and 7 (c). Means \pm standard deviations of survival from a representative of at least two independent experiments are shown; ${ }^{* *} P<0.01$; *** and ${ }^{\# \# \#} P<0.001$ 
Table 2 Sequence reads and alignment statistics for mRNA-seq experiments

\begin{tabular}{|c|c|c|c|c|c|}
\hline & \multicolumn{2}{|c|}{ Keratinocytes } & \multicolumn{3}{|l|}{ K562 } \\
\hline & Untreated & HT $20 \mu \mathrm{M}$ & Untreated & HT $20 \mu \mathrm{M}$ & HT $100 \mu \mathrm{M}$ \\
\hline Total reads & 24780637 & 27833394 & 26397205 & 28428413 & 25594578 \\
\hline Mapped reads & 20517834 & 23032226 & 20403282 & 22398818 & 19973777 \\
\hline$\%$ aligned & 82.8 & 82.8 & 77.3 & 78.8 & 78.0 \\
\hline
\end{tabular}

Table 3 Transcript number and percentage of upregulated or downregulated genes in the three treatment groups

\begin{tabular}{llll}
\hline & $\begin{array}{l}\mathrm{K}^{\prime} \text { cytes, } \\
20 \mu \mathrm{M}\end{array}$ & $\begin{array}{l}\mathrm{K} 562, \\
20 \mu \mathrm{M}\end{array}$ & $\begin{array}{l}\mathrm{K} 562, \\
100 \mu \mathrm{M}\end{array}$ \\
\hline $\begin{array}{l}\text { Number of transcripts } \\
\text { No significant change }\end{array}$ & 26,638 & 27,468 & 26,535 \\
Downregulated & 443 & 152 & 626 \\
$\quad$ Upregulated & 928 & 137 & 915 \\
Percentage of transcripts & & & \\
No significant change & 95.1 & 99.0 & 94.5 \\
Downregulated & 1.58 & 0.55 & 2.23 \\
Upregulated & 3.31 & 0.49 & 3.26 \\
\hline
\end{tabular}
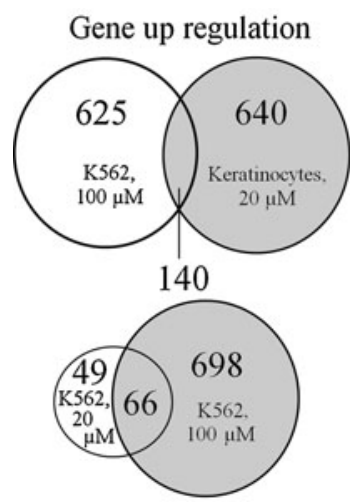

Gene down regulation

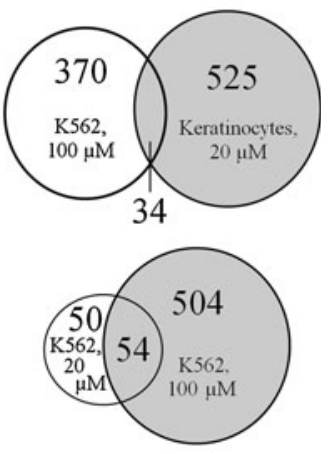

Fig. 7 Venn diagrams showing a comparison between the number of genes upregulated and downregulated in keratinocytes $(20 \mu \mathrm{M})$ and $\mathrm{K} 526$ cells $(100 \mu \mathrm{M})($ top $)$ and $\mathrm{K} 562$ cells of both treatment groups (20 and $100 \mu \mathrm{M})$ (bottom)

Hydroxytyrosol regulates genes associated with inflammation, antioxidant systems and transcription factors

Changes in the expression of genes involved in the cell cycle, DNA repair and replication and apoptosis are shown in Table 4. It is interesting to note the upregulation of the gene for the DNA repair protein Artemis, which has a major role as a nuclease in the non-homologous end-
Table 4 Fold change in gene expression in key pathways following treatment of keratinocytes and K562 cells with hydroxytyrosol

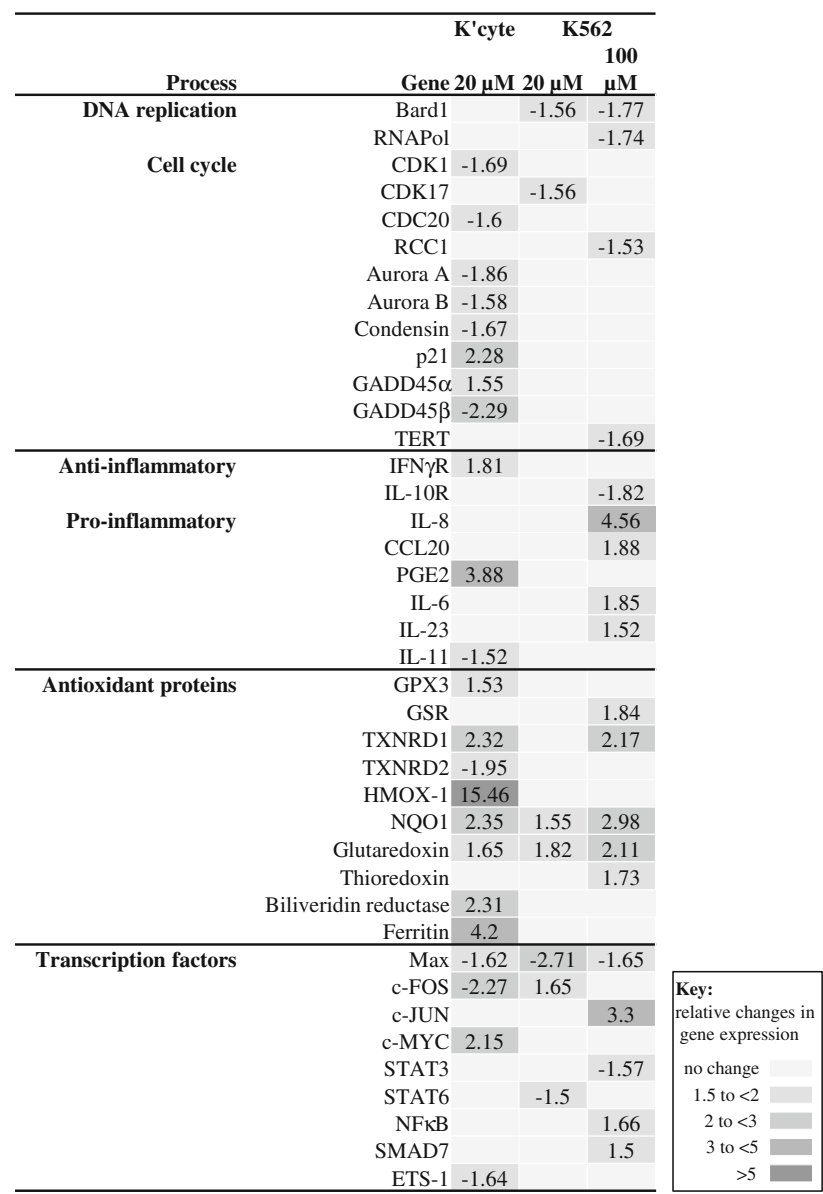

joining DNA double-strand break repair pathway. Table 4 indicates changes in inflammation-associated genes. Upregulation of the IFN $\gamma$ receptor in keratinocytes (1.88fold) and downregulation of the IL-10 receptor in K526 cells $(-1.82)$ were the main observations. Also, upregulation of some proinflammatory cytokines was observed in K562 cells $(100 \mu \mathrm{M})$, including IL-8, IL-6, IL-23 and CCL20, and in keratinocytes, there was upregulation of PGE2 (3.88) and downregulation of IL-11 (-1.52). Table 4 shows changes in the expression of genes involved 
in antioxidant defence systems. There was extensive upregulation of these enzymes in keratinocytes, including heme oxygenase-1 (HO-1), glutaredoxin, thioredoxin reductase 1 , glutathione peroxidase 3 , biliverdin reductase, ferritin and $\mathrm{NAD}(\mathrm{P}) \mathrm{H}$ dehydrogenase, quinone 1 (NQO-1). Changes in the gene expression levels of transcription factors were detected in all cell lines (Table 4). They include the upregulation of $\mathrm{NF} \kappa \mathrm{B}$ (1.66), SMAD7 (1.5) and c-Jun (3.3) and the downregulation of Max $(-1.65)$ and STAT3 $(-1.57)$ in K562 cells $(100 \mu \mathrm{M})$.

\section{Discussion}

The consumption of relatively large quantities of extra virgin olive oil has been long been associated with decreased risk of cardiovascular disease and certain cancers in Mediterranean communities (Huang and Sumpio 2008; Serra-Majem et al. 2003; Alarcon de la Lastra et al. 2001). One minor olive constituent is the polyphenol hydroxytyrosol, which has been identified to be an extremely potent antioxidant and has been shown to induce cell death and apoptosis in a number of cancer cell lines (Bouallagui et al. 2011; Sirianni et al. 2010; Han et al. 2009; Fabiani et al. 2002; Della Ragione et al. 2000). In accordance, our findings indicate that hydroxytyrosol induces dose-dependent cell death and apoptosis in the cancer and transformed cell lines tested (Table 1; Figs. 2, 3).

Expression of one or more ATP-dependent efflux pumps-from the ATP-binding cassette (ABC) transporter family - in the cell membrane of cells results in broad chemoresistance, known as MDR, which remains a major issue in cancer therapy (Litman et al. 2001). The first of these transporters to be identified and characterised was PGP, the product of the MDR1 gene (Ambudkar et al. 2003). We assessed the PGP-modulating activity of hydroxytyrosol using parental CEM-CCRF and R100 (PGP-overexpressing cells) (supplementary Fig. 1). Our findings indicate that R100 cells are less susceptible to cell death and apoptosis than CEM-CCRF cells suggesting efflux by the ABC transporter (Table 1; Fig. 2). Although our results show no changes in cell-surface protein or gene expression levels following treatment with hydroxytyrosol (supplementary Fig. 1), PGP-modulating activity is indicated by the Hoechst 33342 studies (Fig. 4). The findings suggest that concentrations of $\leq 300 \mu \mathrm{M}$ hydroxytyrosol decrease the uptake of Hoechst 33342 in R100 cells (as highlighted by an increase in the fluorescence ratio between CEM-CCRF and R100 cells) (Fig. 4). Considering that Hoechst 33342 could be a surrogate for a DNA-binding chemotherapeutic, these drug interactions could have clinical implications that require further exploration.
Classical studies in the late 1970s indicated that topically applied olive oil protects hamster skin from radiationinduced injury (Smith and Leith 1977). We examined four different olive oil polyphenols-homovanillic alcohol, oleuropein, tyrosol and hydroxytyrosol-for radioprotective activity (supplementary Fig. 2). Initial cell viability assays indicated that hydroxytyrosol reduces radiationinduced cell death (Fig. 5). The findings were corroborated using conventional clonogenic survival assays (Fig. 5). Further, hydroxytyrosol protected from radiation-induced DNA double-strand break formation and from radiationinduced apoptosis (Fig. 6). However, the radioprotective effect is only modest with a dose modification factor of 1.35 being observed in the cell viability studies. These findings are in accordance with recent results indicating that hydroxytyrosol has modest radioprotective activity (Alcaraz et al. 2009).

The antioxidant properties of hydroxytyrosol have been widely investigated. Therefore, we carefully analysed the mRNA-Seq data for regulation of genes associated with antioxidant activity by hydroxytyrosol (Table 4). A key change identified was the 15.5 -fold upregulation of the heme-metabolising enzyme heme oxygenase-1 (HMOX-1; HO-1) in keratinocytes. The breakdown of heme, which is a pro-oxidant, by HO-1 results in the production of biliverdin carbon monoxide and ferrous iron ions. Biliverdin has antioxidant properties and is readily broken down to bilirubin, another potent antioxidant that has been shown to scavenge singlet oxygen. While HO-1 is constitutively expressed in most tissues, it is upregulated in response to oxidative stress via the Nrf-2/ARE pathway (Park et al. 2011; Chen et al. 2011; Kang et al. 2005). The upregulation of HO-1 in keratinocyte cells has important implications for the potential role of HT in cancer prevention and radioprotection by prevention of oxidative stress. HO- 1 has been shown to promote the proliferation of keratinocytes; it is also involved in preventing apoptosis (Petrache et al. 2000; Clark et al. 1997). Its antioxidant role may also help prevent oxidative stress and therefore DNA damage caused by irradiation. In one study, it was identified that nasopharyngeal carcinomas overexpressing HO-1 were more resistant to radiotherapy than those not overexpressing HO-1 (Shi and Fang 2008). This indicates that the mild radioprotection displayed by hydroxytyrosol may occur in part due to the upregulation of HO-1. HO-1 has also been shown to have potent anti-inflammatory properties (Sheikh et al. 2011). HO-1 deficiency has been associated with the increased production of proinflammatory cytokines, such as IL-6, IL-1 $\beta$, TNF and IFN- $\gamma$ in vivo (Kapturczak et al. 2004).

The enzyme biliverdin reductase, which is intimately associated with $\mathrm{HO}-1$, was also found to be upregulated 2.31-fold in keratinocyte cells. The enzyme converts 
biliverdin to bilirubin, which is a potent antioxidant and is involved in cytoprotection and prevention of oxidative stress. It has been shown that downregulating biliverdin reductase with RNAi results in reduced production of bilirubin from biliverdin, and this was associated with an increase in ROS and apoptosis (Baranano et al. 2002). Furthermore, ferritin was upregulated 4.2-fold in keratinocyte cells and is involved in the storage of the pro-oxidant, free iron, which is produced as a heme degradation by-product (Baranano et al. 2002).

Numerous other antioxidant enzymes were also upregulated in keratinocyte cells. Glutaredoxin, part of the thioredoxin superfamily, is involved in maintaining a reduced cellular environment and protects thiol bonds from oxidation during oxidative stress (Meyer et al. 2009). This enzyme is upregulated 1.65-fold in keratinocyte cells. Although the expression of thioredoxin, which has a similar function to glutaredoxin, was not changed in keratinocytes, the enzyme thioredoxin reductase was upregulated 2.32-fold. This enzyme catalyses the reduction of thioredoxin, thus maintaining its functionality (Meyer et al. 2009). Further, we observed the upregulation of glutathione peroxidase 3, an important antioxidant enzyme involved in catalysing the reduction of hydrogen peroxide and lipid hydroperoxides, and $\mathrm{NAD}(\mathrm{P}) \mathrm{H}$ dehydrogenase, quinone 1 (NQO-1) which reduces quinones to hydroquinones, thus preventing the production of radical species. Taken together, it appears that hydroxytyrosol promotes an antioxidant cellular environment which, in the context of cancer prevention, is essential for the protection of DNA and other cell compartments from oxidative stress.

We also interrogated the sequencing data to allow speculation on the possible cancer chemopreventive properties of hydroxytyrosol. It was found that in K562 cells, the expression of telomerase reverse transcriptase (TERT), the main functional subunit of telomerase, was downregulated -1.69-fold (Table 4). Previous studies have shown that K562 cells overexpress TERT and that when down regulated it can lead to cell death (Chakraborty et al. 2006; Yamada et al. 2008). Therefore, this may be a mechanism by which hydroxytyrosol causes cell death in cancerous cells and contributes to cancer prevention as part of an olive oil-rich diet. Another possible mechanism by which olive phenolics could be chemopreventive is by modulation of inflammatory processes, as a proinflammatory cytokine can promote the tumour microenvironment (Table 4) (Colotta et al. 2009). We observed upregulation of the antiinflammatory receptor IFN- $\gamma$ (1.81-fold) and downregulation of the proinflammatory cytokine IL-11 (-1.52-fold) (Sheikh et al. 2011). Further, the effects of hydroxytyrosol on the expression of transcription factors were considered (Table 4). The findings indicate that transcription factors from the signal transducer and activator of transcription (STAT) family were downregulated in K562 cellsSTAT3 and STAT6. STAT3 contributes to the survival of a variety of different tumours, including lung, prostate and squamous cell carcinomas. It has been shown that inhibition of STAT3 in such tumours prevents proliferation and promotes cell apoptosis. Also, it has even been shown that STAT3 knockout mice are resistant to the development of skin tumours (Pedranzini et al. 2004). STAT6 is also overexpressed in a number of cancers (Zhang et al. 2006; Das et al. 2007). For example, overexpression of STAT6 in prostate cancer is associated with increased tumour size, and downregulation results in the induction of apoptosis (Das et al. 2007).

The proto-oncogene c-Fos, which is involved in cell cycle, differentiation and transformation, was found to be downregulated -2.27 -fold in keratinocyte cells. Importantly, c-Fos has been shown to be essential for skin cancer malignant transformation as one experiment showed that knockout mice did not progress to malignant transformation (Saez et al. 1995). Meanwhile, c-Jun was upregulated 3.3-fold in K562 cells. It has been shown that in chronic myeloid leukaemia, BCR-ABL tyrosine kinase downregulates c-Jun expression, promoting neutrophil differentiation in the chronic phase of chronic myeloid leukaemia (Kobayashi et al. 2009). The transcription factor SMAD7 was also found to be upregulated in K562 cells by 1.5-fold, and overexpression of this transcription factor may lead to apoptosis (Yan and Chen 2011). Finally, ETS-1 was found to be downregulated -1.64 -fold in keratinocytes. It has been shown that this transcription factor is upregulated in some squamous cell cancers. This has been correlated with increased metastasis and invasion and may be involved in promoting the epithelial to mesenchymal transition due to the loss of adherence and increased mobility, which may lead to metastasis (Nagarajan et al. 2009).

Overall, our findings provide insights into the mechanisms of action of the olive polyphenol, hydroxytyrosol, in the context of prevention of oxidative stress and cancer chemoprevention. The results highlight significant upregulation of enzymes involved in antioxidant defence systems, most strikingly, HO-1. This indicates that as well as being itself a potent antioxidant, hydroxytyrosol promotes the cells own defences against oxidative stress. Further, we identify potential mechanisms by which hydroxytyrosol may have cancer chemopreventive properties. In general, our sequencing data provide numerous gene targets that may provide the basis for further exploration. Further experiments will involve the investigation into the effects of hydroxytyrosol in cardiac and endothelial cells to provide insights into the potential cardioprotective properties of the polyphenol. 
Acknowledgments The support of the Australian Institute of Nuclear Science and Engineering is acknowledged. TCK was the recipient of AINSE awards. The authors acknowledge JDRF Fellowship support and support from the Foundation for Polish Science. Epigenomic Medicine and Human Epigenetics Labs are supported by the National Health and Medical Research Council of Australia and supported in part by the Victorian Government's Operational Infrastructure Support Program. The authors would like to acknowledge the use of the facilities provided by Monash Micro Imaging @ AMREP and particularly, the expert assistance from Drs Stephen Cody and Iśka Carmichael.

\section{References}

Alarcon de la Lastra C, Barranco MD, Motilva V, Herrerias JM (2001) Mediterranean diet and health: biological importance of olive oil. Curr Pharm Des 7(10):933-950

Alcaraz M, Acevedo C, Castillo J, Benavente-Garcia O, Armero D, Vicente V, Canteras M (2009) Liposoluble antioxidants provide an effective radioprotective barrier. Br J Radiol 82(979):605609. doi:10.1259/bjr/30930369

Ambudkar SV, Kimchi-Sarfaty C, Sauna ZE, Gottesman MM (2003) P-glycoprotein: from genomics to mechanism. Oncogene 22(47):7468-7485. doi:10.1038/sj.onc. 1206948

Baranano DE, Rao M, Ferris CD, Snyder SH (2002) Biliverdin reductase: a major physiologic cytoprotectant. Proc Natl Acad Sci USA 99(25):16093-16098. doi:10.1073/pnas.252626999

Bouallagui Z, Han J, Isoda H, Sayadi S (2011) Hydroxytyrosol rich extract from olive leaves modulates cell cycle progression in MCF-7 human breast cancer cells. Food Chem Toxicol 49(1): 179-184. doi:10.1016/j.fct.2010.10.014

Chakraborty S, Ghosh U, Bhattacharyya NP, Bhattacharya RK, Roy M (2006) Inhibition of telomerase activity and induction of apoptosis by curcumin in K-562 cells. Mutat Res 596(1-2): 81-90. doi:10.1016/j.mrfmmm.2005.12.007

Chen JS, Huang PH, Wang CH, Lin FY, Tsai HY, Wu TC, Lin SJ, Chen JW (2011) Nrf-2 mediated heme oxygenase-1 expression, an antioxidant-independent mechanism, contributes to anti-atherogenesis and vascular protective effects of Ginkgo biloba extract. Atherosclerosis 214(2):301-309. doi:10.1016/j.atherosclerosis. 2010.11.010

Clark JE, Green CJ, Motterlini R (1997) Involvement of the heme oxygenase-carbon monoxide pathway in keratinocyte proliferation. Biochem Biophys Res Commun 241(2):215-220. doi: 10.1006/bbrc.1997.7742

Colotta F, Allavena P, Sica A, Garlanda C, Mantovani A (2009) Cancer-related inflammation, the seventh hallmark of cancer: links to genetic instability. Carcinogenesis 30(7):1073-1081. doi:10.1093/carcin/bgp127

Das S, Roth CP, Wasson LM, Vishwanatha JK (2007) Signal transducer and activator of transcription-6 (STAT6) is a constitutively expressed survival factor in human prostate cancer. Prostate 67(14):1550-1564. doi:10.1002/pros.20640

Della Ragione F, Cucciolla V, Borriello A, Della Pietra V, Manna C, Galletti P, Zappia V (2000) Pyrrolidine dithiocarbamate induces apoptosis by a cytochrome c-dependent mechanism. Biochem Biophys Res Commun 268(3):942-946. doi:10.1006/bbrc.2000. 2161

El SN, Karakaya S (2009) Olive tree (Olea europaea) leaves: potential beneficial effects on human health. Nutr Rev 67(11):632-638. doi:10.1111/j.1753-4887.2009.00248.x

Fabiani R, De Bartolomeo A, Rosignoli P, Servili M, Montedoro GF, Morozzi G (2002) Cancer chemoprevention by hydroxytyrosol isolated from virgin olive oil through G1 cell cycle arrest and apoptosis. Eur J Cancer Prev 11(4):351-358

Gonzalez-Santiago M, Martin-Bautista E, Carrero JJ, Fonolla J, Baro L, Bartolome MV, Gil-Loyzaga P, Lopez-Huertas E (2006) Onemonth administration of hydroxytyrosol, a phenolic antioxidant present in olive oil, to hyperlipemic rabbits improves blood lipid profile, antioxidant status and reduces atherosclerosis development. Atherosclerosis 188(1):35-42. doi:10.1016/j.atherosclerosis. 2005.10.022

Granados-Principal S, Quiles JL, Ramirez-Tortosa CL, SanchezRovira P, Ramirez-Tortosa MC (2010) Hydroxytyrosol: from laboratory investigations to future clinical trials. Nutr Rev 68(4):191-206. doi:10.1111/j.1753-4887.2010.00278.x

Han J, Talorete TP, Yamada P, Isoda H (2009) Anti-proliferative and apoptotic effects of oleuropein and hydroxytyrosol on human breast cancer MCF-7 cells. Cytotechnology 59(1):45-53. doi: 10.1007/s10616-009-9191-2

Huang CL, Sumpio BE (2008) Olive oil, the mediterranean diet, and cardiovascular health. J Am Coll Surg 207(3):407-416. doi: 10.1016/j.jamcollsurg.2008.02.018

Huertas JR, Battino M, Barzanti V, Maranesi M, Parenti-Castelli G, Littarru GP, Turchetto E, Mataix FJ, Lenaz G (1992) Mitochondrial and microsomal cholesterol mobilization after oxidative stress induced by adriamycin in rats fed with dietary olive and corn oil. Life Sci 50(26):2111-2118

Hurlin PJ, Kaur P, Smith PP, Perez-Reyes N, Blanton RA, McDougall JK (1991) Progression of human papillomavirus type 18-immortalized human keratinocytes to a malignant phenotype. Proc Natl Acad Sci USA 88(2):570-574

Kang KW, Lee SJ, Kim SG (2005) Molecular mechanism of nrf2 activation by oxidative stress. Antioxid Redox Signal 7(11-12): 1664-1673. doi:10.1089/ars.2005.7.1664

Kapturczak MH, Wasserfall C, Brusko T, Campbell-Thompson M, Ellis TM, Atkinson MA, Agarwal A (2004) Heme oxygenase-1 modulates early inflammatory responses: evidence from the heme oxygenase-1-deficient mouse. Am J Pathol 165(3):10451053. doi:10.1016/S0002-9440(10)63365-2

Kobayashi S, Kimura F, Ikeda T, Osawa Y, Torikai H, Kobayashi A, Sato K, Motoyoshi K (2009) BCR-ABL promotes neutrophil differentiation in the chronic phase of chronic myeloid leukemia by downregulating c-Jun expression. Leukemia 23(9):16221627. doi:10.1038/leu.2009.74

Litman T, Druley TE, Stein WD, Bates SE (2001) From MDR to MXR: new understanding of multidrug resistance systems, their properties and clinical significance. Cell Mol Life Sci 58(7): 931-959

Marrugat J, Covas MI, Fito M, Schroder H, Miro-Casas E, Gimeno E, Lopez-Sabater MC, de la Torre R, Farre M (2004) Effects of differing phenolic content in dietary olive oils on lipids and LDL oxidation-a randomized controlled trial. Eur J Nutr 43(3):140 147. doi:10.1007/s00394-004-0452-8

Mataix J, Ochoa JJ, Quiles JL (2006) Olive oil and mitochondrial oxidative stress. Int J Vitam Nutr Res 76(4):178-183. doi: 10.1024/0300-9831.76.4.178

Member S, Bruger M (1945) Experimental atherosclerosis; the effect of feeding olive oil on the absorption and deposition of cholesterol. Arch Pathol (Chic) 40:373-375

Meyer Y, Buchanan BB, Vignols F, Reichheld JP (2009) Thioredoxins and glutaredoxins: unifying elements in redox biology. Annu Rev Genet 43:335-367. doi:10.1146/annurev-genet-102108-134201

Nadtochiy SM, Redman EK (2011) Mediterranean diet and cardioprotection: the role of nitrite, polyunsaturated fatty acids, and polyphenols. Nutrition 27(7-8):733-744. doi:10.1016/j.nut.2010. 12.006

Nagarajan P, Parikh N, Garrett-Sinha LA, Sinha S (2009) Ets1 induces dysplastic changes when expressed in terminally-differentiating 
squamous epidermal cells. PLoS One 4(1):e4179. doi:10.1371/ journal.pone.0004179

Okey R, Harris A, Scheier G, Lyman MM, Yett S (1959) Effect of olive oil and squalene on cholesterol mobilization in the rat. Proc Soc Exp Biol Med 100(1):198-201

Park SY, Park DJ, Kim YH, Kim Y, Kim SG, Shon KJ, Choi YW, Lee SJ (2011) Upregulation of heme oxygenase-1 via PI3 K/Akt and Nrf-2 signaling pathways mediates the anti-inflammatory activity of Schisandrin in Porphyromonas gingivalis LPS-stimulated macrophages. Immunol Lett. doi:10.1016/j.imlet.2011.05.007

Pauwels EK (2011) The protective effect of the mediterranean diet: focus on cancer and cardiovascular risk. Med Princ Pract 20(2):103-111. doi:10.1159/000321197

Pedranzini L, Leitch A, Bromberg J (2004) Stat3 is required for the development of skin cancer. J Clin Invest 114(5):619-622. doi: 10.1172/JCI22800

Petrache I, Otterbein LE, Alam J, Wiegand GW, Choi AM (2000) Heme oxygenase-1 inhibits TNF-alpha-induced apoptosis in cultured fibroblasts. Am J Physiol Lung Cell Mol Physiol 278(2): L312-L319

Puel C, Mardon J, Agalias A, Davicco MJ, Lebecque P, Mazur A, Horcajada MN, Skaltsounis AL, Coxam V (2008) Major phenolic compounds in olive oil modulate bone loss in an ovariectomy/inflammation experimental model. J Agric Food Chem 56(20):9417-9422. doi:10.1021/jf801794q

Puertollano MA, Puertollano E, Alvarez de Cienfuegos G, de Pablo MA (2007) Significance of olive oil in the host immune resistance to infection. Br J Nutr 98(Suppl 1):S54-S58. doi: 10.1017/S0007114507832934

Quiles JL, Ramirez-Tortosa MC, Huertas JR, Ibanez S, Gomez JA, Battino M, Mataix J (1999) Olive oil supplemented with vitamin E affects mitochondrial coenzyme Q levels in liver of rats after an oxidative stress induced by adriamycin. Biofactors 9(2-4): 331-336

Raederstorff D (2009) Antioxidant activity of olive polyphenols in humans: a review. Int J Vitam Nutr Res 79(3):152-165. doi: 10.1024/0300-9831.79.3.152

Saez E, Rutberg SE, Mueller E, Oppenheim H, Smoluk J, Yuspa SH, Spiegelman BM (1995) c-fos is required for malignant progression of skin tumors. Cell 82(5):721-732

Serra-Majem L, de la Cruz JN, Ribas L, Salleras L (2003) Mediterranean diet and health: is all the secret in olive oil? Pathophysiol Haemost Thromb 33(5-6):461-465. doi:10.1159/ 000083846

Sheikh SZ, Hegazi RA, Kobayashi T, Onyiah JC, Russo SM, Matsuoka K, Sepulveda AR, Li F, Otterbein LE, Plevy SE
(2011) An anti-inflammatory role for carbon monoxide and heme oxygenase-1 in chronic Th2-mediated murine colitis. J Immunol 186(9):5506-5513. doi:10.4049/jimmunol.1002433

Shi L, Fang J (2008) Implication of heme oxygenase-1 in the sensitivity of nasopharyngeal carcinomas to radiotherapy. J Exp Clin Cancer Res 27:13. doi:10.1186/1756-9966-27-13

Sirianni R, Chimento A, De Luca A, Casaburi I, Rizza P, Onofrio A, Iacopetta D, Puoci F, Ando S, Maggiolini M, Pezzi V (2010) Oleuropein and hydroxytyrosol inhibit MCF-7 breast cancer cell proliferation interfering with ERK1/2 activation. Mol Nutr Food Res 54(6):833-840. doi:10.1002/mnfr.200900111

Smith PP, Leith JT (1977) Effects of topically-applied olive oil on the response of hamster skin to single or multiple doses of $230 \mathrm{kV}$ X-rays. Int J Radiat Biol Relat Stud Phys Chem Med 31(5): $467-475$

Trichopoulou A, Lagiou P, Kuper H, Trichopoulos D (2000) Cancer and mediterranean dietary traditions. Cancer Epidemiol Biomarkers Prev 9(9):869-873

van den Heuvel-Eibrink MM, Wiemer EA, Prins A, Meijerink JP, Vossebeld PJ, van der Holt B, Pieters R, Sonneveld P (2002) Increased expression of the breast cancer resistance protein (BCRP) in relapsed or refractory acute myeloid leukemia (AML). Leukemia 16(5):833-839. doi:10.1038/sj.leu.2402496

Vandesompele J, De Preter K, Pattyn F, Poppe B, Van Roy N, De Paepe A, Speleman F (2002) Accurate normalization of real-time quantitative RT-PCR data by geometric averaging of multiple internal control genes. Genome Biol 3(7):RESEARCH0034

Visioli F, Bernardini E (2011) Extra virgin olive oil's polyphenols: biological activities. Curr Pharm Des 17(8):786-804

Wagner $\mathrm{H}$ (1957) The fatty acid composition of rats after feeding with butter, margarine, olive oil and sunflower oil. Int Z Vitaminforsch Beih 28(1-2):192-193

Yamada O, Kawauchi K, Akiyama M, Ozaki K, Motoji T, Adachi T, Aikawa E (2008) Leukemic cells with increased telomerase activity exhibit resistance to imatinib. Leuk Lymphoma 49(6): 1168-1177. doi:10.1080/10428190802043861

Yan X, Chen YG (2011) Smad7: not only a regulator, but also a crosstalk mediator of TGF-beta signalling. Biochem J 434(1):1-10. doi:10.1042/BJ20101827

Yaqoob P, Knapper JA, Webb DH, Williams CM, Newsholme EA, Calder PC (1998) Effect of olive oil on immune function in middle-aged men. Am J Clin Nutr 67(1):129-135

Zhang MS, Zhou YF, Zhang WJ, Zhang XL, Pan Q, Ji XM, Luo ZG, Wu JP (2006) Apoptosis induced by short hairpin RNAmediated STAT6 gene silencing in human colon cancer cells. Chin Med J (Engl) 119(10):801-808 